\title{
The Use of Dust Suppression on Unpaved Roads at the Mining Allotment of the Kuzbass Mine
}

\author{
Tatyana Cherkasova ${ }^{1,}$, Elizaveta $_{\text {Cherkasova }}{ }^{1}$, Anastasia Tihomirova $^{1}$, Alexey \\ Andryushkov $^{1}$, and Oleg Dormeshkin ${ }^{2}$ \\ ${ }^{1}$ T.F. Gorbachev Kuzbass State Technical University, 650000, Russian Federation \\ ${ }^{2}$ Belarusian State Technological University, Minsk, Belarus
}

\begin{abstract}
Marker substances for the coal mining industry were identified as an information and technical reference book to the best available technologies for coal mining and processing. Inorganic dust when emitted into the atmosphere is defined as a marker substance for the coal industry. Inorganic dust emissions belong to the group of fugitive emissions which are carried out from large areas. For the solving of the mentioned problem on the territory of Mine no.12 in Kiselevsk city, it was proposed to use the Anti-dust and the Bischofit products.
\end{abstract}

\section{Introduction}

Air pollution in the area of coal mining enterprises depends on climatic and mininggeological conditions. Thus strong winds create conditions for the intensification of the dust entry into the surface layers of the atmosphere and the movement of dust in them. Even at a windspeed of $2 \mathrm{~m} / \mathrm{s}$, dry dust is blown away and carried over considerable distances. The construction of high dumps also contributes to the growth of dust emissions into the atmosphere since the wind speed increases as their height increases [1-7].

The solving of the relevant mine technical task aimed to increase the efficiency and safety of mining operations during the development of the mining allotment of the Mine no.12, LLC is economically and socially important and inextricably connected with the improvement of methods for fixing dusty surfaces at the objects of the mining complex.

The atmospheric air pollution by dust during mining is to the great extend caused by open fugitive dust emission sources, the main of which are dusty surfaces of warehouses, waste dumps, roads [8-15].

Hence, the goal of the study is to establish dust suppression efficiency when using the Anti-dust product of the brand D of the engineering company Brent, LLC and the Bishofit product of the JSC Kaustic on dirt roads at the mining allotment of the Mine no.12, LLC.

The research solves the following tasks:

- A comparative analysis of the concentration of dust blown from the surface treated with the Anti-dust product of the brand D and the Bishofit product, and non-treated surface;

\footnotetext{
*Corresponding author: ctg.htnv@kuzstu.ru
} 
- Determination of the resistance to atmospheric precipitation of the surface treated with the Anti-dust product of the brand $\mathrm{D}$ and the Bishofit product;

- Determination of the optimal dosages of the reagent for using the Anti-dust product of the brand $\mathrm{D}$ on dirt roads at the mining allotment of Mine no.12, LLC taking into account characteristics of the treated surface and weather conditions.

\section{Research method}

The research object was the dirt road of the Mine no.12, LLC (Kiselevsk city, Kemerovo region). In 2013 it was decided to develop open-cut mining and cease dangerous supercategory underground mining. The annual production level of coal of grades $\mathrm{K}$ and $\mathrm{T}$ amounts to over 730 thousand tons.

The quality of atmospheric air is due to the ratio of certain substances in air composition. People's health, vegetation and wildlife state, strength and durability of any structures, buildings and structures depend on the air quality.

The main sources of air pollution are natural and man-made processes.

The formation of atmospheric air quality in the city of Kiselevsk is influenced by various factors, including the degree of industrialisation, the existence of highway systems with heavy traffic, as well as geographical location and climate pattern.

Within the framework of the study the industrial tests of the Anti-dust and the Bishofit dust suppression products were conducted on a dirt road section. The surface was treated by irrigation without prior preparation.

The dust suppression Anti-dust product has the characteristics presented in the Tables 12 .

Table 1. Technical characteristics of the Anti-dust product of brand D.

\begin{tabular}{|c|c|c|}
\hline No & Indicator & Brand D \\
\hline 1. & Appearance & Transparent liquid \\
\hline 2. & $\begin{array}{c}\text { The content of active substances } \\
\text { is not less, } \%\end{array}$ & 30 \\
\hline 3. & Density, $\mathrm{kg} / \mathrm{dm}^{3}$ & $1,20-1,30$ \\
\hline 4. & $\begin{array}{c}\text { Temperature range of application } \\
\text { of the resulting solution, }{ }^{\circ} \mathrm{C}\end{array}$ & $-40 \ldots+40$ \\
\hline 5. & $\begin{array}{c}\text { Temperature range of operation } \\
\text { of reinforced soil, }{ }^{\circ} \mathrm{C}\end{array}$ & $-30 \ldots+40$ \\
\hline
\end{tabular}

Table 2. The field of utilization and consumption rates of the Anti-dust product of brand D.

\begin{tabular}{|c|c|c|c|}
\hline & Field of utilization & $\begin{array}{c}\text { Consumption per } \\
\mathbf{1 ~ m}^{\mathbf{2}} \\
\text { product+water, litre }\end{array}$ & Retreatment \\
\hline 1. & $\begin{array}{c}\text { Roads, roadsides (horizontal } \\
\text { section) }\end{array}$ & $0,05+1$ & $5-7$ days \\
\hline 2. & $\begin{array}{c}\text { Roads, erosion control on } \\
\text { slopes (steep slope) }\end{array}$ & $0,05+1$ & $3-5$ days \\
\hline 3. & Dedusting a surface & $0,05+1$ & $5-7$ days \\
\hline
\end{tabular}




\begin{tabular}{|c|c|c|c|}
\hline 4. & $\begin{array}{c}\text { Dedusting of coal during } \\
\text { carriage }\end{array}$ & $0,25+1$ & 5 days \\
\hline 5. & $\begin{array}{c}\text { Dedusting of coal upon } \\
\text { storage in cones in open } \\
\text { sections }\end{array}$ & $0,25+1$ & $3-5$ days \\
\hline 6. & $\begin{array}{c}\text { Dust suppression in places } \\
\text { of coal and bulk materials } \\
\text { transshipment }\end{array}$ & 2 litres of $5,0 \%$ solution per 1 ton of coal \\
\hline
\end{tabular}

The surface treated by irrigation does not require any preparation.

Depending on the specific goals and conditions various methods and options for surface treatment with the Anti-dust product of brand D are possible. The most common and convenient way is the irrigation method.

The irrigation method consists in uniform distribution of the previously prepared composition of the product over the surface using sprayers. As a result of irrigation the composition penetrates into the soil to a certain depth and binds it.

The Bishofit product absorbs moisture from the air and keeps it on the road for a long time. Having such a property as hygroscopicity (strong capacity to absorb moisture even from relatively dry air), Bishofit provides maximum moisture of the road surface. It does not allow dust to rise and hang in the air. This moisture-absorbing effect provides greater dust suppression compared to water. In addition, Bishofit extends the work lifespan of the roadway providing the soil stabilisation.

Dry (crystalline) magnesium chloride is dissolved in water in the ratio $1: 1$.

The consumption of the Bishofit solution - from 0,1 litre $/ \mathrm{m}^{2}$ depending on the type of the highway, traffic density and means of transport, dustiness of the area as well as the nature of the dust.

The Bishofit solution processing steps:

- Dissolution of the crystalline reagent on the mixing unit or directly in the tank of Multipurpose Road Maintenance Vehicle;

- Distribution of reagent solution to the surface counting from $0,1 \mathrm{litre} / \mathrm{m}^{2}$;

-The highway is ready for use.

The duration of the reagent when using the specified proportions (period of use of the treated highway without dust):

- using grader equipment - 10 days;

- non-treated with a grader -30 and more days.

The treatment of the tested sections was carried out with the use of the Anti-dust product of brand $\mathrm{D}$ of the engineering company Brent, LLC and the Bishofit product of the JSC Kaustic. The sections surface was treated at a temperature of $+27^{\circ} \mathrm{C}$ at mainly clear weather with northwester at a windspeed of $2 \mathrm{~m} / \mathrm{s}$ counting 0,3 и 0,25 litre per $1 \mathrm{~m}^{2}$ of the Anti-dust and the Bishofit products respectively.

The concentrations of dust blown from the treated and non-treated sections surface were measured using the equipment that simulates the erosive effect of wind on the soil surface at the maximum possible wind loads of up to $25 \mathrm{~m} / \mathrm{s}$.

The installation diagram for the measuring of dust concentrations blown from the surface of treated and non-treated sections is shown at the Figure 1. 


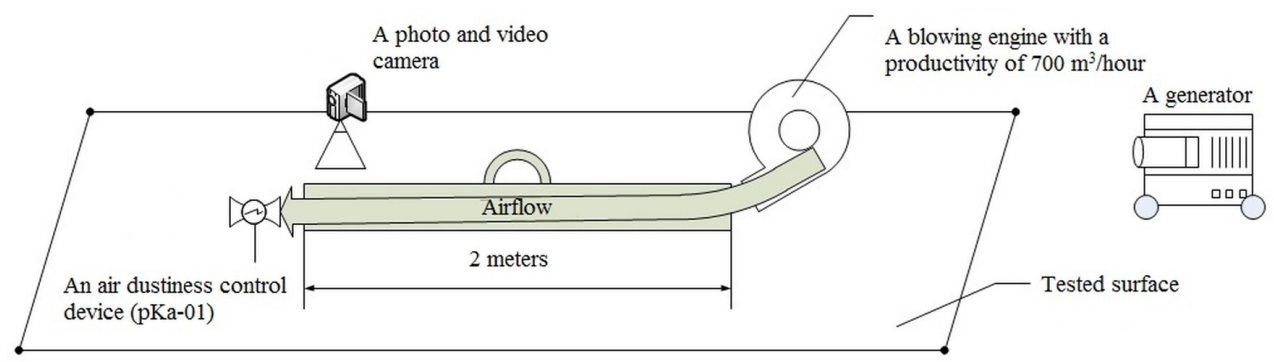

Fig. 1 The installation diagram.

Used equipment:

- A blowing engine with a productivity of $700 \mathrm{~m}^{3} /$ hour;

- An air conduit for creating a given airflow rate;

- An air dustiness control device (pKa-01);

- A photo and video camera;

- A generator.

An air conduit ( 2 meters long and 0.1 meters wide) was installed on the tested surface (for direct impact on a specific surface section and excluding external factors). A blowing engine was installed on one side of the air conduit; pKA-01 air dustiness control device and photo and video camera were installed on the other side of the air conduit.

\section{Key findings}

Table 3 presents the key findings of the study.

After measuring the concentration of dust at all sections, it was decided to stop the subsequent control of section no.2 due to the fact that the Bishofit product did not prove its effectiveness. Measurements were taken at section no.1 treated with the Anti-dust product, and at the non-treated section.

Retreatment of the section no. 1 was carried out with the Anti-dust product of brand D at $5 \%$ concentration $\left(0,05\right.$ litre $\left./ \mathrm{m}^{2}\right)$. The product was applied to a damp surface at air temperature of $+26^{\circ} \mathrm{C}$ in a cloudy weather with a north wind at a windspeed of $4 \mathrm{~m} / \mathrm{s}$.

Table 3. Dust Measurement Results.

\begin{tabular}{|c|c|c|c|c|c|c|}
\hline \multirow[t]{2}{*}{ Date } & \multicolumn{3}{|c|}{ Weather } & \multicolumn{3}{|c|}{ Dust concentration, $\mathrm{mg} / \mathrm{m}^{3}$} \\
\hline & $\begin{array}{c}t \text { - air } \\
\text { temperature, } \\
{ }^{\circ} \mathrm{C}\end{array}$ & $\begin{array}{c}V- \\
\text { windspeed, } \\
\mathrm{m} / \mathrm{s}\end{array}$ & Precipitation & Anti-dust & Bishofit & Non-treated \\
\hline 01.08 .2019 & 29 & 3 & clear & 29,3 & 813,1 & 909,2 \\
\hline 02.08 .2019 & 29 & 3 & clear & 40,6 & - & 925,8 \\
\hline 03.08 .2019 & 31 & 3 & clear & 109,4 & - & 1335,5 \\
\hline
\end{tabular}

By the end of the second testing day after the retreatment, the Anti-dust product began to lose its effectiveness and it was decided to treat the section with water in order to prolong its effect.

The following findings were obtained during the tests:

1. The Bishofit product did not prove the declared dust suppression charachteristics;

2. The Anti-dust product of brand D at a primary treatment effectively suppresses dust for four days; 
3. After retreatment the Anti-dust product effectively suppresses dust for three days;

4. After watering the section treated with the Anti-dust product on the third day, the effective dust suppression is extended up to 12 hours.

\section{Conclusions}

Based on the results of the tests the declared dust suppression characteristics were confirmed and the optimal concentrations of the Anti-dust product of the brand D of the engineering company Brent, LLC were determined, which made it possible to reduce the amount of blown dust on various surfaces of road sections at the mine allotment of Mine no.12, LLC.

\section{References}

1. R. Zeng, X. Zhuang, N. Koukouzas, W. Xu, Int. J. Coal Geol, 61, 833 (2005)

2. R.N. Peres, E.S.F. Cardoso, M.F. Montemor, H.G. Melo, A.V. Benedetti, P.H. Suegama, Surf Coat Technol (Part B), 303, 372 (2016)

3. F. Khelifa, M-E. Druart, Y. Habibi, F. Bénard, P. Leclère, M. Olivier, P. Dubois, Prog Org Coat, 76, 900 (2013)

4. B. Volarič, I. Corros Eng Sci Technol, 52, 201 (2017)

5. R. D. Kiggins, The Political Economy of Rare Earth Elements Rising Powers and Technological Change (Palgrave Macmillan, London, 2015)

6. K. Binnemans, Y. Pontikes, P. T. Jones, T. Van Gerven, B. Blanpain, International Slag Valorisation Symposium, 3, 191-205 (2013)

7. K. Binnemans, P. T. Jones, B. Blanpain, T. Van Gerven, Y. Pontikes, Journal of Cleaner Production, 99, 17-38 (2015)

8. B. N. Kumar, S. Radhika, M. L. Kantam and B. R. Reddy, J. Chem. Technol. Biot., 86:4, 562-569 (2011)

9. L.S. Wang, Z.Q. Long, X.W. Huang, Y. Yu, D.L. Cui G.C. Zhang, Hydrometallurgy, 101:1-2, 41-47 (2010)

10. P. M. Reza, P. Norouzi, H. Rashedi, M. R. Ganjali, J Appl Electrochem, 40, 1593-1603 (2010)

11. K. Shunsuke, K. Yuichi, K. Hiroshi, W. Kazuaki, Open Journal of Physical Chemistry, 3, 69-75 (2013)

12. H. El-Didamony, M. M. Ali, N. S. Awwad, M. M. Fawzy and M. F. Attallah, J. Radioanal. Nucl. Chem., 291:3, 907-914 (2012)

13. Tran X., Elsevier. ScienceDirect, 163, 129-132 (2016)

14. F. Wojciech, M.M. Wiatros-Motyka, M. Wdowin, Environmental Science and Pollution Research, 22, 9464-9474 (2015)

15. C.N. Lange, M.C Camargo, G. M. Figueiredo, B.A. Vasconcellos, R.B. Ticianelli, Journal of Radioanalytical and Nuclear Chemistry, 311, 1235-1241 (2017) 